\title{
Onchocerca volvulus heat shock protein 70 is a major immunogen in amicrofilaremic individuals from a filariasis-endemic area
}

\author{
Neil M. Rothstein ${ }^{1}$, Gene Higashi ${ }^{2}$, John Yates ${ }^{3}$ and Thiruchandurai V. Rajan ${ }^{1}$ \\ ${ }^{1}$ Departments of Microbiology and Immunology and Pathology, Albert Einstein College of Medicine, Bronx, NY, U.S.A., \\ ${ }^{2}$ Department of Epidemiology, University of Michigan, Ann Arbor, MI, U.S.A. and ${ }^{3}$ Department of Biological Science, Oakland \\ University, Rochester, MI, U.S.A.
}

(Received 2 August 1988; accepted 27 October 1988)

\begin{abstract}
Infestation with organisms causing lymphatic filariasis (i.e. Wuchereria bancrofti and Brugia malayi) results in a variety of clinical presentations. It is possible that some of the variation is due to differences in host response to parasite. To determine whether individuals who live in an endemic area but differ in their clinical manifestations respond to different filarial antigens, we screened Onchocerca volvulus expression libraries with sera from a number of individuals belonging to different clinical groups. The results of the study demonstrate that there are indeed differences in the recognition of three cloned filarial antigens and that this differential recognition is related to clinical symptomatology. The most striking finding is that an Onchocerca volvulus protein homologous to the $70 \mathrm{kDa}$ Xenopus laevis heat shock protein is primarily recognized by individuals who are amicrofilaremic. Further analysis is required to determine whether these antigens play any role in the pathogenesis of filarial infection or have any potential value in protective immunity.
\end{abstract}

Key words: Filariasis; Onchocerca volvulus; Heat shock protein 70; Immunoscreening

\section{Introduction}

Lymphatic filariasis is a major public health problem in a number of Third World nations, with an estimated 90 million cases worldwide [1]. Globally, the primary causative organism of lymphatic filariasis is Wuchereria bancrofti; infection with Brugia malayi is found mainly in Malaysia and Indonesia. The manifestations of the disease are protean [2]. In an endemic area where transmission of the parasite is presumably occurring at a high rate, a vast majority of individuals (up to

Correspondence address: N.M. Rothstein, Department of Pathology, University of Connecticut Health Center, 263 Farmington Ave., Farmington, CT 06105, U.S.A.

Abbreviations: TPE, tropical pulmonary eosinophilia; HSP70, $70 \mathrm{kDa}$ heat shock protein.

Note: Nucleotide sequence data reported in this paper have been submitted to the GenBank ${ }^{\mathrm{TM}}$ Data Bank with the accession number $\mathrm{J} 04006$.
$70 \%$ ) do not show any symptom of disease. These individuals, referred to as 'endemic normals', often have circulating antibodies to the parasite and can therefore be assumed to have had exposure to it. Another group of individuals (ranging from $10-20 \%$ of the population) can be demonstrated, on routine blood smears, to be microfilaremic, but are asymptomatic. A small percentage of individuals (1-5\%) present with acute clinical symptoms including filarial fevers, lymphadenitis and lymphangitis. About $1 \%$ of the population exhibit chronic symptoms, primarily the sequelae of chronic lymphatic blockage. In addition, in the Indian subcontinent, there exists a small minority of patients who present with symptoms of immediate hypersensitivity in the form of asthmatic episodes. This condition is referred to as tropical pulmonary eosinophilia (TPE).

The precise mechanism responsible for this varied clinical presentation is not clear. It is widely assumed that the parasite itself is invariant and 
that the clinical presentation is dependent upon host factors, of which the immune response may be one. We have undertaken to screen filarial expression libraries to define whether the various subsets of individuals in an endemic zone differ in the antigens they recognize.

\section{Materials and Methods}

Source of patient sera. Peripheral blood was obtained from villagers residing in a well characterized area endemic for $W$. bancrofti filariasis in Andhra Pradesh, India [3]. Samples were obtained from endemic normals without history of clinical filariasis and negative blood smears for microfilariae, microfilaremic individuals who were without clinical signs or symptoms and chronic clinical filariasis patients with lymphadenitis, lymphedema, hydrocoele or elephantiasis and without microfilaremia. The age range was $12-60$ years with female to male ratio of 1.28 . Sera were collected and stored at $-20^{\circ} \mathrm{C}$ until used.

Screening expression libraries with patient sera. cDNA libraries derived from RNA of Onchocerca volvulus, the causative organism of ocular filariasis, were obtained from Dr. John Donelson, Iowa University, Iowa [4] and screened as described by Huyhn et al. [5]. In summary, phage were plated on a lawn of Escherichia coli $\mathrm{K}-12$ strain Y1090 and grown at $42^{\circ} \mathrm{C}$. Once plaques were visible, the plates were overlaid with nitrocellulose filter papers soaked in $10 \mathrm{mM}$ IPTG. After 1-2 $\mathrm{h}$ of induction, the nitrocellulose filters were removed, and blocked in a $3 \%$ gelatin solution in Tris-buffered saline (TBS $=50 \mathrm{mM}$ Tris $\mathrm{pH} 8.0,0.9 \%$ saline). The filters were incubated overnight with gentle rocking in sera diluted 1:100 in $1 \%$ gelatin/TBS. After extensive washing with TBS, they were incubated with an anti-immunoglobulin $G$ second antibody conjugated to horseradish peroxidase. After $3 \mathrm{~h}$, they were again washed extensively and treated with substrate. Positive clones were picked in comparison with a wild type gt 11 control.

The libraries were initially screened with a rabbit anti- $B$. malayi serum or with pooled human sera purified and rescreened to insure plaque purity. Pure clones were rescreened with individual sera.
Subcloning and sequencing. We subcloned the $\lambda$ gt11 inserts into pUC18 [6] with a double-digestion of $K p n I$ and $S a c I$, which cut $\lambda g t 11$ approximately a kilobase on either side of the EcoRI site. This allowed us to perform dideoxynucleotide sequencing [7] using oligonucleotides specific for the $\lambda$ gt11 flanking sequence (New England Biolabs, Beverly, MA) and to determine the orientation and reading frame of our inserts. Double-stranded sequencing was performed using either the $E$. coli polymerase I Klenow fragment, or the Sequenase $^{\mathrm{R}}$ kit (U.S. Biochemical Co., Cleveland, $\mathrm{OH}$ ). Further sequence analysis was accomplished by subcloning into pUC18.

\section{Results}

Screening libraries with rabbit xenoserum and patient sera. By screening the $O$. volvulus cDNA expression libraries with the rabbit antiserum, we obtained 113 positive clones, of which 33 were plaque purified. 15 of these clones were recognized by pooled patient sera. Screening the libraries with pooled endemic normal sera yielded 5 clones.

Patterns of reactivity of various clones with individual sera. Table I summarizes the results obtained by screening nine clones with sera from various patient groups. Although most sera from endemic normal individuals recognize different clones with a few overlaps, many (7/14) recognize G15. One other point worth noting is that clone $\mathrm{K} 11$ is not recognized by most endemic normal individuals. G15 is seen by a majority of the sera from patients with chronic symptoms and K11 by fewer. In contrast to the endemic normals and chronic patients, TPE sera recognize a large number of clones and there is considerable overlap among the sera. In contrast to those patients who are endemic normal or have chronic symptoms, patients with asymptomatic microfilaremia recognize clone K11 at high frequency (6/9) and G15 less frequently.

Identification of clones of interest. Based on our analysis of individual sera, we focused on a few of the clones that appear to demonstrate patterns of reactivity. Thus, K11 is seen primarily by pa- 


\section{TABLE I}

Reactivity of recombinant clones with sera from various patient groups

\begin{tabular}{|c|c|c|c|c|c|c|c|c|c|}
\hline \multirow[t]{2}{*}{ Sera } & \multicolumn{9}{|c|}{ Clones } \\
\hline & K8 & K11 & $\mathrm{K} 14$ & G3 & G15 & M4 & ME2 & ME8 & TE1 \\
\hline \multicolumn{10}{|c|}{ Endemic normal screen } \\
\hline N2 & & & & & + & & & & + \\
\hline N5 & & $+1-$ & $+1-$ & & + & + & & & \\
\hline N7 & & & & & & & $+1-$ & $+1-$ & \\
\hline N9 & & & & & $+1-$ & + & & + & \\
\hline $\mathrm{H} 3$ & & & & & & & & $+1-$ & \\
\hline H8 & & & & & & & & $+1-$ & \\
\hline $\mathrm{H} 13$ & & & & & + & & & & \\
\hline $\mathrm{H} 16$ & + & + & & & & & & & \\
\hline $\mathrm{H} 19$ & & & & & + & & $+1-$ & $+1-$ & \\
\hline H34 & & & & & + & & & & \\
\hline $\mathrm{H} 35$ & & + & & & & & & & \\
\hline $\mathrm{H} 36$ & & & & & + & & & $+1-$ & \\
\hline $\mathrm{H} 37$ & + & & & & + & $+1-$ & $+1-$ & $+1-$ & \\
\hline $\mathrm{H} 40$ & $+1-$ & & & & & & & & \\
\hline \multicolumn{10}{|c|}{ Chronic pathology } \\
\hline $\mathrm{H} 1$ & & & & & + & & & & \\
\hline H5 & & & & & & & $+1-$ & $+1-$ & \\
\hline $\mathrm{H} 15$ & & + & & & + & & & & \\
\hline $\mathrm{H} 17$ & $+1-$ & + & & & + & & & $+1-$ & \\
\hline $\mathrm{H} 42$ & & & & & + & & & & \\
\hline $\mathrm{H} 46$ & & & & & + & & & & \\
\hline \multicolumn{10}{|c|}{ Tropical eosinophilia } \\
\hline $\mathrm{N} 22$ & + & + & + & & + & + & & $+1-$ & \\
\hline $\mathrm{H} 2$ & & + & + & + & + & + & & $+1-$ & \\
\hline $\mathrm{H} 3$ & & + & + & & & + & & & \\
\hline $\mathrm{H} 4$ & & $+1-$ & + & + & $+1-$ & + & & & \\
\hline H5 & & & & & & & & $+1-$ & \\
\hline \multicolumn{10}{|c|}{ Asymptomatic microfilaremic } \\
\hline $\mathrm{H} 7$ & & & & & & & & + & \\
\hline H14 & & + & & & & & & $+1-$ & \\
\hline H18 & & + & & & & & $+1-$ & & \\
\hline $\mathrm{H} 20$ & & + & & & & & $+1-$ & + & \\
\hline $\mathrm{H} 22$ & + & + & & & + & + & & $+1-$ & \\
\hline $\mathrm{H} 23$ & + & + & & & & & & + & \\
\hline $\mathrm{H} 26$ & & & & & & & & $+1-$ & \\
\hline $\mathrm{H} 27$ & & & & & & & + & & \\
\hline $\mathrm{H} 29$ & + & + & & & & & & + & \\
\hline
\end{tabular}

+ , greater reactivity than $\lambda g t 11$ control; $+/-$, weak positive. A blank space denotes background or less than background reactivity.

tients who are microfilaremic, while G15 is seen primarily by patients who are amicrofilaremic. The identity of K11 will be discussed in a separate publication. Clone ME8 appears to be recognized weakly by large numbers of individuals. Two other clones, K14 and M4, are recognized predominantly by TPE patients. Partial sequence analysis has not established the identity of these inserts.

The sequence of G15 is shown in Fig. 1. The nucleic acid homology revealed significant but by no means overwhelming homology with nucleic acid sequences in the GENBANK library. However, when the inferred protein sequence was 
1 GluPhelysArgAsnAsplysLysAspleu AlaSerAsnProArgAla LeuArgArgLeu GAATTCAAGCGTAACGATAAGAAAGATCTT GCTTCGAACCCTCGCGCACTTCGTCGACTG CTTAAGTTCGCATTGCTATTCTTTCTAGAA CGAAGCTTGGGAGCGCGTGAAGCAGCTGAC

61 ArgThralaCysGluArgalaLysArgThr LeuSerSerSerSerglnalaserIleglu CGTACTGCTTGTGAAAGAGCGAAACGAACA CTCTCTAGTTCATCTCAAGCGAGTATCGAG GCATGACGAACACTTTCTCGCTTTGCTTGT GAGAGATCAAGTAGAGTTCGCTCATAGCTC

121 IleAspSerLeuPheGluGlyIleAspPhe TyrThrAsnIleThrArgAlaArgPheGlu ATTGATTCTTTGTTCGAGGGGATCGATTTT TACACAAACATTACGCGTGCCCGTTTTGAA TAACTAAGAAACAAGCTCCCCTAGCTAAAA ATGTGTTTGTAATGCGCACGGGCAAAACTT

181 GluLeuCysAlaAspLeuPheArgSerThr MetAspProvalgluLysAlaLeuArgval GAACTATGTGCTGATTTGTTCCGCTCAACC ATGGATCCGGTTGAGAAAGCATTGCGTGTC CTTGATACACGACTAAACAAGGCGAGTTGG TACCTAGGCCAACTCTTTCGTAACGCACAG

AlaLysMetAspLysAlaglnValHisAsp IleValLeuValGlyGlySerThrArgIle

241 GCCAAGATGGATAAAGCTCAAGTTCATGAC ATTGTACTAGTAGGTGGATCAACGCGTATT CGGTTCTACCTATTTCGAGTTCAAGTACTG TAACATGATCATCCACCTAGTTGCGCATAA

ProLysValGlnLysLeuLeuSerAspPhe PheSerGlyLysGluLeuAsnLysSerIle 301 CCGAAAGTACAGAAACTTCTCTCAGATTTC TTCTCTGGCAAAGAACTGAATAAAAGTATT GGCTTTCATGTCTTTGAAGAGAGTCTAAAG AAGAGACCGTTTCTTGACTTATTTTCATAA

AsnProAspgluAlaValAlaTyrglyAla AlaValGlnAlaAlaIleLeuSerglyAsp 361 AATCCAGATGAAGCTGTGGCATATGGTGCA GCAGTACAAGCAGCTATTCTTTCTGGTGAT TTAGGTCTACTTCGACACCGTATACCACGT CGTCATGTTCGTCGATAAGAAAGACCACTA

LysSerGluAlaValGInAspLeuLeuLeu LeuAspValAlaProLeuSerLeuGlyI le AAATCGGAAGCCGTACAGGACTTGTTGTTA CTCGACGTCGCACCACTTTCACTTGGTATT TTTAGCCTTCGGCATGTCCTGAACAACAAT GAGCTGCAGCGTGGTGAAAGTGAACCATAA GAAACAGCTGGAGGTGTTATGACTGCTCTT ATTAAGCGGAACACTACTATCCCAACGAAA CTTTGTCGACCTCCACAATACTGACGAGAA TAATTCGCCTTGTGATGATAGGGTTGCTTT

ThrSerGlnThrPheThrThrTyrSerAsp AsnGlnProGlyValLeuIleGlnValTyr

541 ACGTCTCAAACATTTACCACATACTCCGAT AATCAGCCTGGTGTTCTTATTCAGGTTTAT TGCAGAGTTTGTAAATGGTGTATGAGGCTA TTAGTCGGACCACAAGAATAAGTCCAAATA

GluGlyGluArgAlaMetThrLysAspAsn AsnLeuLeuGlyLysPheGluLeuSerGly 601 GAAGGTGAACGTGCTATGACGAAAGACAAT AATCTGCTTGGTAAATTCGAATTGTCTGGA CTTCCACTTGCACGATACTGCTTTCTGTTA TTAGACGAACCATTTAAGCTTAACAGACCT

IleProProAlaProArgGlyValProGln IleGluValThrPheAspIleAspAlaAsn

661 ATTCCGCCTGCTCCTCGCGGTGTGCCGCAA ATTGAAGTCACATTCGATATTGACGCGAAT TAAGGCGGACGAGGAGCGCCACACGGCGTT TAACTTCAGTGTAAGCTATAACTGCGCTTA

GlyI leLeuAsnValserAlaglnAspLys SerThrGlyLysGlnAsnLysIleThrIle 721 GGTATTTTGAATGTTTCCGCACAAGATAAA TCAACAGGAAAACAGAACAAGATTACAATT CCATAAAACTTACAAAGGCGTGTTCTATTT AGTTGTCCTTTTGTCTTGTTCTAATGTTAA

ThrAsnAspLysGlyArgLeuSerLysAsp GluIleGluArgMetValGlnGluAlaGlu

781 ACCAATGACAAAGGACGTTTGTCAAAGGAT GAGATTGAGCGAATGGTACAGGAAGCTGAG TGGTTACTGTTTCCTGCAAACAGTTTCCTA CTCTAACTCGCTTACCATGTCCTTCGACTC

LysTyrLysAlaAspAspGIUAlaGlnLys AspArgIleAlaAlaLysAsnAlaLeuGlu

841 AAATATAAGGCGGATGATGAAGCACAGAAA GATCGTATTGCAGCGAAAAATGCTCTCGAA TTTATATTCCGCCTACTACTTCGTGTCTTT CTAGCATAACGTCGCTTTTTACGAGAGCTT

SerTyrAlaPheAsnMetLysGlnThrIle GluAspGluLys LeuLysAspLys IleSer

901 TCTTATGCATTCAATATGAAACAAACGATC GAGGACGAAAAGCTGAAAGACAAGATTTCG AGAATACGTPAGTTATACTTTGTTTGCTAG CTCCTGCTTTTCGACTTTCTGTTCTAAAGC

GluPhe

961 GAATTC

CTTAAG

Fig. 1. The nucleic acid sequence of the G15 insert and its inferred amino acid sequence. 
subjected to computer analysis, the sequence showed a striking level of identity to both the Xenopus laevis heat shock protein 70 (HSP70) [8] and the rat heat-shock cognate protein [9] (Fig. 2 ). Note that the N-terminal 285 amino acids exhibit significant conservation ( $92 \%$ identity) with the sequence of $X$. laevis HSP70, and the remaining 36 amino acids considerable divergence (65\% identity) from the sequence. This level of divergence suggests to us the possibility that the antibody reactivity that we have observed may be specific for filarial heat-shock protein rather than a cross-reaction with the heat-shock proteins of other agents to which the patients may have been exposed. However, we would like to follow this up by separating these two domains and obtain more convincing data in this regard.

\section{Discussion}

The introduction of the techniques of molecular biology to the study of tropical diseases has made possible the identification of protein antigens that may be of immunological relevance. However, one must anticipate that most patients exposed to a parasitic organism will develop immune responses to a large and potentially bewildering array of antigens. The analysis of antigens recognized by individuals exhibiting different clinical symptoms may ultimately lead to strategies of control or diagnosis. The analogy we would like to draw here is the success that workers in the field of Schistosomiasis have had using mouse strains that are permissive or restrictive to infection [10]. By comparing the immune response of two defined groups of mice, it has been possible to identify antigens that correlate with recovery

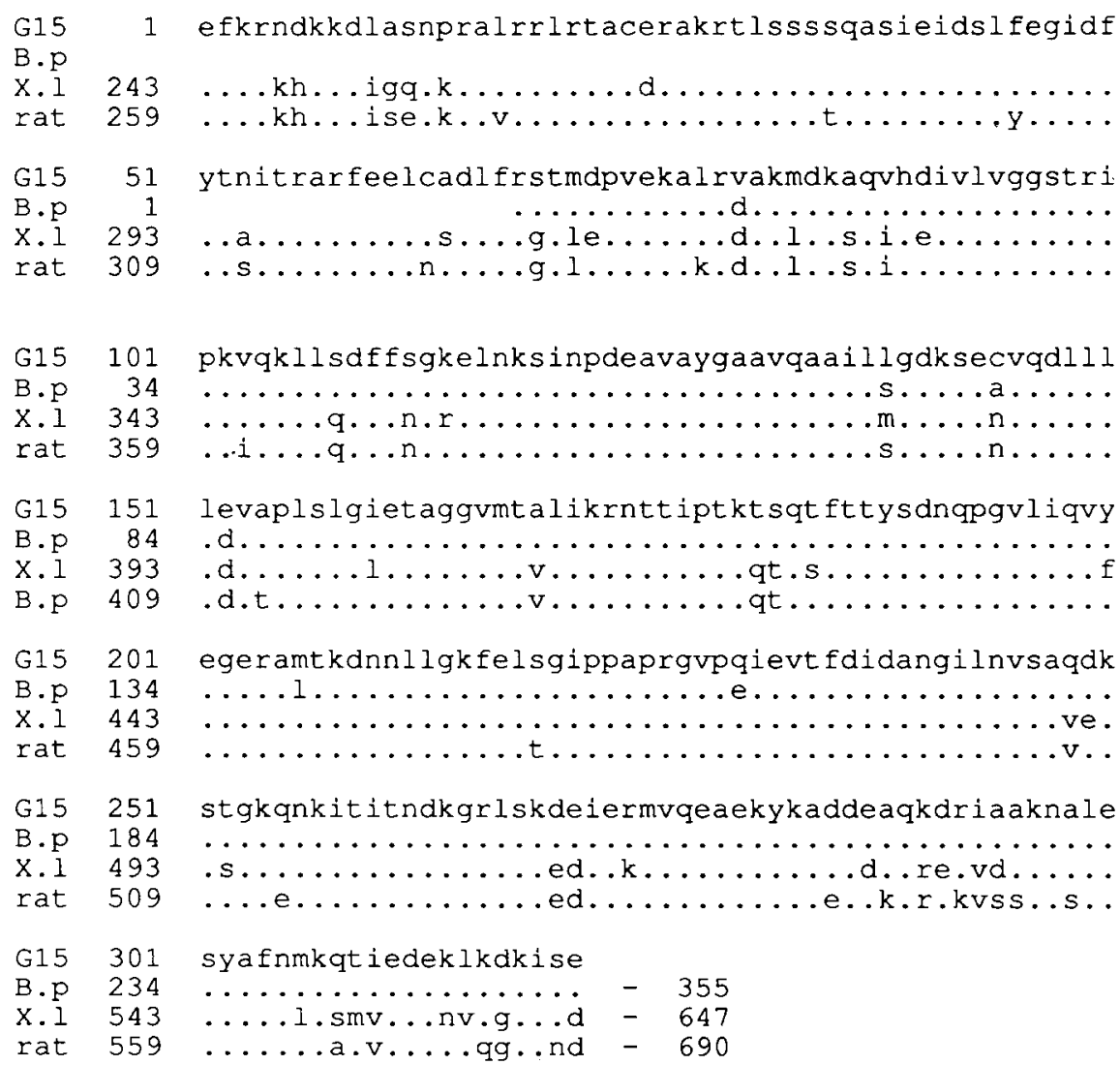

Fig. 2. The amino acid alignment of the G15 insert with $B$. pahangi HSP70 like protein (B.p) [17], $X$. laevis HSP70 (X.1) [7] and rat heat shock cognate protein (rat) [8]. (.) depicts identity with the G15 sequence; a blank denotes unavailable sequence. 
from disease. The homogeneity of inbred mice makes such analysis straightforward. The lack of a well-defined murine model for filariasis necessitates the use of a somewhat less-defined patient population to achieve the same goals. Because of the heterogeneity of the human population at the large number of genetic loci that are involved in the immune response, it must be expected that even patients within a given clinical spectrum will show considerable variation in the profile of antigens to which they respond. Indeed, we have found that most patients recognize quite different protein antigens, with the exception of the protein encoded by ME8, which appears to be recognized by many. In addition, it is entirely possible that the current classifications encompass a range of clinical pictures with subtle differences that have yet to be delineated. For instance, endemic normals may represent a variety of patients, some of whom have been exposed to infection and have successfully dealt with it, whereas others have had insufficient exposure to cause establishment of infection.

Nevertheless, using this approach, we have screened a number of libraries using sera from various patient groups to determine if they recognize different antigens. Although we have used libraries that are not homologously matched (our sera are from patients suffering from infection with $W$. bancrofti and the libraries were derived from $O$. volvulus), this approach is vindicated by the fact that the patient sera clearly recognize antigens derived from the related but non-homologous organism. We find this to be not particularly surprising since sequence analysis so far suggests considerable conservation of coding regions between the filarial organisms (data not shown).

The identity of G15 as a heat shock protein is of interest. We must emphasize that we are referring to G15 as a 'heat shock' protein for lack of a felicitous alternative term, since sequence homology with the heat shock family of genes does not necessarily imply that G15 is heat inducible. Thus, certain constitutive proteins share homology with members of the heat shock family and several members are inducible by stresses other than heat. With these caveats, a number of groups have shown that stress response proteins are important immunogens in parasitic infections
[11-13]. In its transition from the cold-blooded arthropod vector to the warm-blooded mammalian host, the infective third stage filarial larva undergoes a significant temperature shift. In addition, to return to the above mentioned possibility of inducibility by agents other than heat, exposure to other factors in the host's serum, such as free radicals [14], is likely to induce a stress response. This response, which may play a role in developmental regulation of several organisms and has been postulated to act as a pathogenic switch [15], may trigger the moult to the fourth stage larva. It is tempting to speculate that an active immune response to protein involved in the stress response may play a role in aborting further development of the incoming larva.

It is striking that patients who have dealt successfully with and eliminated infections, namely patients with chronic pathology and endemic normals, appear to have active immune responses to HSP70. This response may be gratuitously produced upon stress and subsequent killing of an infective larva by as yet unknown mechanisms or may inherently be involved in the recognition and killing of the parasite. Yet another possibility is that the response we have observed is not specific for filarial organisms at all, but is adventitious and represents a cross reaction of G15 with antibodies to stress proteins from other organisms to which the individuals had been exposed. This argument appears unlikely, since one has to explain why only amicrofilaremic individuals mount this response. Nonetheless this is a formal possibility and we are attempting to determine whether the antibodies are specific to filarial proteins by performing appropriate absorptions.

Our data are essentially in agreement with those of Selkirk et al. [16], who have used similar protocols to define antigens differentially recognized by filarial patients. By screening $B$. pahangi libraries with patient sera, they isolated a clone encoding an HSP70-like protein [17] and found it to be recognized primarily by amicrofilaremic individuals. This clone differs from our sequence at 6 of 321 residues, but, overall, the sequence identity is nearly complete (Fig. 2). Based on the homology of their sequence with other proteins, Selkirk et al. have suggested that their antigen may be a heat shock cognate protein - a protein 
that shares sequence homology with the heat inducible proteins but is itself constitutive. We have referred to our antigen as a 'heat shock' protein, implying homology but not necessarily inducibility by heat or any other stress. We are presently isolating full length genomic clones corresponding to G15 to determine whether canonical heat shock response sequences are present $5^{\prime}$ of this gene; at the same time we are investigating the kinetics of production of transcripts derived from this gene to define the level, if any, of inducibility

\section{References}

1 Mak, J.W. (1986) Epidemiology of lymphatic filariasis. In: Symposium on Filariasis (Evered, D. and Clark, S., eds.), Ciba Found. Symp. 127, 5-14.

2 Partono, F. (1986) The spectrum of disease in lymphatic filariasis. In: Symposium on Filariasis (Evered, D. and Clark, S., eds.), Ciba Found. Symp. 127, 15-31.

3 Rao, C.K., Datta, K.K., Sundaram, R.M., Ramaprasad, K., Sundara Rao, J., Venkatanaryana, M., Nath, V.V.N., Krishna Rao, P., Krishna Rao, Ch., Das, M. and Sharma, S.P. (1980) Epidemiological studies on bancroftian filariasis in East Godavari District (Andhra Pradesh): Base line filariometric indices. Ind. J. Med. Res. 71, 712-722.

4 Donelson, J.E., Duke, B.O.L., Moser, D., Zeng, W., Erondu, N.E., Lucius, R., Renz, A., Karam, M. and Flores, G. (1988) Construction of Onchocerca volvulus cDNA libraries and partial characterization of the cDNA for a major antigen. Mol. Biochem. Parasitol. 31, 241-250.

5 Huynh, T.V., Young, R.A. and Davis, R.W. (1985) Constructing and screening cDNA libraries in $\lambda \mathrm{gt} 10$ and $\lambda \mathrm{gt} 11$. In: DNA Cloning, A Practical Approach (Glover, D.M., ed.), Vol. I, pp. 49-78, IRL Press, Washington, DC.

6 Yanisch-Perron, C., Vieira, J. and Messing, J. (1985) Improved M13 phage cloning vectors and host strain: $\mathrm{Nu}-$ cleotide sequences of the M13mp18 and pUC19 vectors. Gene 33, 103-119.

7 Sanger, F., Nicklen, S. and Coulson, A.R. (1977) DNA sequencing with chain-terminating inhibitors. Proc. Natl. Acad. Sci. USA 74, 5463-5467.

8 Bienz, M. (1984) Xenopus hsp 70 genes are constitutively expressed in injected oocytes. EMBO J. 3, 2477-2483.

9 O'Malley, K., Mauron, A., Barchas, J.D. and Kedes, L. (1985) Constitutively expressed rat mRNA encoding a 70kilodalton heat-shock-like protein. Mol. Cell Biol. 5, 3476-3483. in response to various known stress agents. These data, in combination, should establish the true nature of this protein.

\section{Acknowledgements}

This work was made possible by a grant from the Irvington House Institute for Medical Research. We would like to thank Dr. Tom Nutman for the rabbit antiserum used in the initial screen.

10 Lanar, D.E., Pearce, E.J., James, S.J. and Sher, A. (1986) Identification of paramyosin as schistosome antigen recognized by intradermally vaccinated mice. Science 234 , 593-596.

11 Young, D.B., Lahtigra, R., Hendrix, R., Sweetser, D. and Young, R. (1988) Stress proteins are immune targets in leprosy and tuberculosis. Proc. Natl. Acad. Sci. USA 85, $4267-4270$.

12 Bianco, A.E., Favaro, J.M., Burkot, T.R., Gulvenor, J.G., Crewther, P.E., Brown, B.V., Anders, R.F., Coppel, R.L. and Kemp, D.J. (1986) A repetitive antigen of Plasmodium falciparum that is homologous to heat shock protein 70 of Drosophila melanogaster. Proc. Natl. Acad. Sci. USA 83, 8713-8717.

13 Hedstrom, R.C., Culpepper, J.A., Schinski, V., Agabian, N. and Newport, G.R. (1988) Schistosome heat shock proteins are immunologically distinct host like antigens. Mol. Biochem. Parasitol. 29, 275-282.

14 Christman, M.F., Morgan, R.W., Jacobson, F.S. and Ames, B.N. (1985) Positive control of a regulon for defense against oxidative stress and some heat-shock proteins in Salmonella typhimurium. Cell 41, 753-762.

15 Van der Ploeg, L.H.T., Grannini, S.H. and Cantor, C.R. (1985) Heat shock genes: regulatory role for differentiation in parasitic protozoa. Science 228, 1443-1446.

16 Selkirk, M.E., Rutherford, P.J., Bianco, A.E., Flint, J.E., Denham, D.A., Partono, F. and Maizels, R.M. (1987) Characterization and cloning of lymphatic filarial antigens. U.C.L.A. Symp. Mol. Biol. New Ser. 60, 169-181.

17 Selkirk, M.E., Rutherford, P.J., Denham, D.A., Partono, F. and Maizels, R.M. (1987) Cloned antigen genes of Brugia filarial parasites. Biochem. Soc. Symp. 53, 91-102. 